\title{
Publication Quality Indicators for Tenure or Promotion Decisions: What Can the Librarian Ethically Report?
}

\section{Barbara A. Rice and Tony Stankus}

Academic faculties are becoming increasingly aware of the many capabilities of Science Citation Index, ${ }^{1}$ Social Sciences Citation Index, ${ }^{2}$ and Arts $\&$ Humanities Citation Index. ${ }^{3}$ These indexes are used for subject searching, for obtaining lists of publications by a given author, for determining centers of certain types of research, for comparative evaluations of academic departments, and for evaluation of peers in tenure and promotion considerations. Although considerable controversy surrounds the use of citation counts for the latter practice, they are being used in such evaluations. It is not the purpose of this paper to reexamine or enter into the controversy surrounding the use of citation data in promotion or tenure considerations. The literature on this subject is voluminous. We wish to discuss the impact of online availability of citation data and provide information relating to provision and interpretation of search results by librarians. In addition, we recommend other types of information which the librarian should suggest to patrons in order to supplement citation data, or to be used when citation data is nonexistent or appears incomplete.

\section{ONLINE CITATION SEARCHING}

Until quite recently a patron wishing to determine whether or not a given author's works were cited could do a manual search of the appropriate citation index and come up with a tally, or more often, a tally and listing of who was citing the author being evaluated. In order to do an effective search it was necessary to under- stand how the index worked, and it is likely, although not guaranteed, that the searcher would read the introductory material to learn how to do the search and become aware of some of the difficulties inherent in compiling a listing which are due to the nature of the index. For example, in doing a manual search it is likely that the patron would become aware of the fact that only the first author is listed in the citation index and that, by tracing the citation to the source index, would realize that there might be more than one author of the same name. However, with the advent of online availability of these indexes, this is no longer the case. A patron can bring in a list of references, leave them with a searcher, and return to pick up a list of citations. Although Caldwell and Livingston ${ }^{4}$ state that "citation indexes provide a way to determine how highly valued and widely read the research produced by your faculty is, " we caution that the process is not as simple as running an online search, as these authors imply.

The librarian performing a citation search has an ethical responsibility to inform the patron of the nature of the citation index being searched, with the inherent limitations this places on the search. The patron should also be provided with information on known citation practices in the evaluation field and references to the literature, which give caveats relating to the application of the references obtained in evaluation procedures.

Before attempting the search, the searcher should discuss the list of references with the patron to ensure that it is complete, and that the patron understands the search process. It is frequently

Barbara A. Rice is principal librarian for reference services, New York State Library, and Tony Stankus is science librarian, Science Library, College of the Holy Cross, Worcester, Massachusetts. 
the case that the person gathering the information sends a graduate student to deliver the list and, if required by the library, participate in the search interview or search process. The librarian should not permit this. The limitations of the index and search capabilities are difficult to explain and the searcher should not assume that the student will convey all information to the requester.

During the interview the searcher should examine the submitted bibliography carefully to see that references are complete and that actual first authors are given. Cited items are listed only by the first author in the citation indexes. Therefore, simply doing a search to find items citing Jane A. Doe will find only those papers which list her as sole author or first author, but will not retrieve those papers where she is second or third author unless the first author is provided.

Whether or not this is important is discussed by Garfield. ${ }^{5}$ It is decidedly important that the requester know whether or not his bibliography is accurate in this respect and, if not, what qualifications this imposes on the search results.

The patron must also be made aware of the scope of the particular citation index being searched and be shown the list of journals covered. Each citation index covers the most heavily cited journals in each field covered, but there are certain academic specialties for which the source journals might not be a very comprehensive list of works citing the author being evaluated. A quick way to check is to see whether the author's own papers are listed in the journals as possible citations. If a majority are not, the searcher should advise the patron of the alternative strategies discussed later in this paper.

Another difficulty sometimes encountered is that the index cannot distinguish between two people having the same last name and first initial, who may be publishing during the same time period. The patron should understand the necessity for examining the search results carefully for entries that seem to be in a field different from the author being evaluated.

\section{COMPARATIVE CITATION PRACTICES IN DIFFERENT FIELDS}

As Garfield points out, "It certainly is improper to make comparisons between citation counts generated in different fields. ${ }^{\prime \prime}$ Not only are there differences with respect to the average number of citations in a given field, but there are differences with respect to the type of material cited, e.g., mathematicians cite books more often than chemists. Science Citation Index and Social Sciences Citation Index primarily examine journal sources for citations.

What then can the searcher give to the patron relating to citation practices in different fields? It is recommended that the user be given a reprint of Garfield's chapter entitled "Perspective on Citation Analysis of Scientists" for a summary of known norms in the sciences. In actuality, limited information is available, but it should encourage the user to consider what norms should be used and what significance any raw number of citations, whether 0 or 5 or 500 , means in the field where the information supplied is to be used. The average annual citation rate for a scientific paper is only 1.7 and many papers published are not cited at all. Endler, ${ }^{8}$ in studying Canadian psychologists using Social Sciences Citation Index, reports that during 1975, 40 percent of those studied had zero citations and three out of every five had two citations or less. "A disproportionately large amount of citations and publications is accounted for by a disproportionately small number of individuals," Endler stated. Helmreich ${ }^{9}$ also points out that there are large sex differences in citation rates among psychologists and analyzes possible causal factors.

If no norms are known for the candidate's field, it is conceivably possible to construct them using the following technique: the patron supplies a list of departments considered to be of comparable nature (e.g., size, national reputation, student body, etc.). Using the corporate source index of the appropriate citation index, the number of papers from each of these institutions is tallied. Then an aver- 
age number of papers per faculty member can be obtained by dividing the total number of papers by the number of faculty. This could be done for one year, or, preferably, for several years. Such techniques have been used for comparing institutions. ${ }^{10,11,12}$ Alternatively, the records of only those faculty from these peer institutions whose specialization matches that of the candidates could be found.

As noted earlier, Science Citation Index and Social Sciences Citation Index examine predominantly journal sources for citations. Citations appearing in most books are not included, although books cited in the journals scanned are. Citation counts may or may not include citations to book reviews, and what would seem apparent here is that it is not as important to know whether or not there was a review, as it is to know what the review stated as to the quality and importance of the book being reviewed. A librarian should know the major review sources in any field and can assist the patron compiling the information for the promotion or tenure review to ferret out reviews should the candidate's vita include books as well as journals.

The searcher should inform the patron that a library staff member, knowledgeable in the use of citation indexes, is available to discuss the search results and interpret the results and other techniques which should be considered in order to obtain as complete information as possible on citations to the work of the individual being evaluated.

The use of the citation data in promotion and tenure processes has been urged as a quantitative, objective standard of evaluation. Given the little that is known about norms, it does not seem that citation data is yet a wholly effective tool in this respect. What if no norms are known for the candidate's field? What if the candidate's publications are very recent and have not yet been cited, or cited comparatively little? What then? The librarian, in addition to supplying information on known norms, should suggest other information relating to the journals in which the candidate has published which can be of use in the evaluation process.

Information about the quality of the journals within which the candidate being evaluated has published can easily be supplied by librarians. An evaluator may wish to consider some or all of the following factors in addition to or in lieu of citation information.

- What is the purpose of the journal?

- Who publishes the journal?

- What types of articles does it carry?

- Who are the editors and referees?

- What role do the editors and referees play in the acceptance or publication process?

- What institutions are represented among contributors?

- Who are the individual contributors?

\section{JOURNAL PURPOSE, PUBLISHER, AND TYPES OF PAPERS}

Journals cited in the vita may be characterized by purpose, publisher background and specialization, and the nature of the papers being published. There are many for-profit firms, university press, and professional societies which are known to be quality publishers. Most librarians can list publishers of known repute in various academic disciplines. The librarian, however, should not report unsubstantiated hearsay, but should instead gather factual information for analysis. This may be types of journals published, e.g., scholarly versus popular, general fields in which the publisher specializes, e.g., scientific, legal, etc., and the number of journal titles published. If the publisher is a society, then information on the society's membership and purpose should be reported.

The type(s) of paper(s) carried is also a consideration in evaluating the nature of the candidate's contribution. For example, is it a review journal or does it consist of original research contributions? Is it an informal news bulletin-an alumni journal, for example? Is the contribution of the candidate a full-length article? Book review? Brief communication? Letter to the editor? Are there special requirements for publication, e.g., membership or alumnus status? While some of this information may be known to the individual requesting the information, it may not all be 
known, nor may it be known uniformly through the department or by other persons or review bodies which are often involved in the evaluation process, such as a campus-wide promotion and tenure committee or the vice-president or president of the college or university. Samples of specific information which a librarian might compile follow.

1. The Journal of " $A$ " Studies, founded in 1948, publishes about 200 eight-to-fifteenpage contributed, original research papers each year in the general field indicated by the title. It also publishes monthly society personnel news, an editorial, five to ten book reviews, and job placement notices. It is sponsored by the Society for " $\mathrm{A}$ " Research and Treatment, located in New York, which has a membership of 12,000 . Membership is open to those with an M.D. or Ph.D. in an appropriate discipline who demonstrate an interest in the field and can provide references from two established members. Membership is not necessary for acceptance of an article, although members do not have to pay page charges. The candidate is a member and the publications 1 and 5 in his vita represent a research article of standard length for this journal and a standard length, 200word book review, respectively.

2. The " $B$ " Review has been published by the Midwestern University press since 1975. It is the only journal published by them. Each year it publishes approximately 30 twenty-to-forty-five-page surveys of recent developments in law and politics. Articles are written largely by its own students, faculty, and alumni. It appears on a trimester basis with the spring issue listing biographies of honorarydegree recipients, the text of commencement speeches, and a directory of recent graduates. The candidate is an alumnus of this institution. His contribution, number 8 on the vita, is a letter to the editor criticizing the choice of an honorary degree recipient and rebutting that recipient's article in a prior issue.

3. Acta " $\mathrm{C}$ " Internationalis has been published since 1960 by Alexandrian Press, a for-profit scientific, technical, and medical publishing house which currently publishes about 300 journals in New York,
Paris, London, and Vienna. Acta " $\mathrm{C}$ " Internationalis is a bimonthly organic chemistry journal which carries an annual total of approximately 70 twenty-to-twenty-fivepage overviews of recent research, approximately 400 eight-to-twelve-page contributed articles, approximately 250 four-to-six-page brief communications, and approximately 300 paragraph abstracts of presentations at professional symposia in the field. Publications 1, 2, and 3 on this candidates vita are abstracts from the symposia. Item 4 is a brief communication of the results announced in the first abstract, and item 5 is an article of standard length elaborating on the findings of the second and third abstracts.

\section{JOURNAL RANKINGS AND REJECTION RATES}

Another possible way of describing the importance of a given journal is to use Journal Citation Reports, an annual compilation which is part of Science Citation Index and Social Sciences Citation Index, which rank journals in several ranking packages, e.g., total citations and impact factor. The experiences of author Stankus working with use of impact factors to provide information on science journals in promotion and tenure decisions has been that stronger candidates have published in journals with relatively high impact factors.

Rejection rates are a piece of information that is not always readily available, but in some cases can be found by digging through the front matter of journals, or in the annual reports of publishing houses or societies. The information is usually available on request from the editor or publisher.

\section{EDITORS, REFEREES, AND CONTRIBUTORS}

Another important consideration in journal quality is the prestige of its editors and referees. While there is no guarantee that all members of an editorial board are actively involved in the journal, or that stated refereeing policies are followed, information about the reputations of the editors and referees can be gathered from biographical directories. For example, 
American Men and Women of Science can supply an outline of factual information. A quick literature search can establish the extent of a given editor's or referee's own publication history. Compilations of academic institutional evaluations, e.g., Anderson \& Roose's Rating of Graduate Programs, can give an idea of the degree of distinction of the program with which the editor or referee is affiliated. Some sample information that might be supplied follows.

1. The editors of Journal " $\mathrm{X}$ "' are Jones, Harvard University; Smith, University of Chicago; and Johnson, University of California, Berkeley. Jones, Smith, and Johnson are all full professors in programs rated by Anderson \& Roose as distinguished. Jones and Johnson are members of the National Academy of Sciences. Manuscripts are read by one of the editors plus two outside referees of his choosing.

2. " $Y$ " Journal has more than sixty listed editors. A sampling shows that slightly more than half are affiliated with clinical programs in drug and alcohol abuse, while the remainder are equally divided between highly rated schools of social work or psychology. Manuscripts are sent to the editor in chief who designates three of the editors as referees.

3. The Yearbook of the " $Z$ " State University Teaching Effectiveness Workshops is edited by a committee drawn from the chairpersons of the departments of education at each of the university's branches. Workshop faculty and all working teachers who plan to attend furnish an outline of their presentation three months before the meeting for review by all members of the board. Approximately 10 percent are selected for general presentation at the meeting and subsequent printing in full in the yearbook. The remaining are accepted for poster presentations with subsequent printing as one-page summaries.

In addition to evaluating editors, all of whom may have been selected for high repute in their fields, it is also possible to sample contributors. Virtually every author makes some commitment to a journal by having submitted a paper to it. An author's choice of journals lives on in personal biographies which the author (if academic) is aware will be reviewed by tenure or promotion committees, for grant proposals, etc. In the aggregate, academic departments gain a reputation by publishing in the best journals, and the best journals are characterized by repeatedly publishing the work of the best departments. Consequently, librarians can use online techniques to sample departments to see which have contributed to a journal in which the candidate has published.

\section{CONCLUSION}

Academic librarians who are asked to supply information for tenure or promotion decisions have an ethical responsibility not only to supply the requested information but to educate the requester in the limitations of any search techniques used (manual or online) and the types of factual information that can be supplied. Librarians should require from requesters that they participate in the search process (especially in the case of online searches) and provide a clear statement of what is being asked for. The authors believe that the issues raised in this article merit serious discussion by academic librarians, which would result in statements of library policy with respect to library participation in provision of information to faculties for promotion or tenure consideration.

\section{REFERENCES}

1. Science Citation Index (Philadelphia: Institute for Scientific Information, 1961- ).

2. Social Sciences Citation Index (Philadelphia: Institute for Scientific Information, 1973- ).

3. Arts and Humanities Citation Index (Philadelphia: Institute for Scientific Information, 1980- ).

4. Jane L. Caldwell and Celia S. Livingston, "On-Line Bibliometrics," BRS Brief Paper Series, no.4:2 (Jan. 1980).

5. Eugene Garfield, "Perspective on Citation Analysis of Scientists" in his Citation Indexing-Its Theory and Application in Science, Technology and Humanities (New York: Wiley, 1979). 
6. Ibid., p. 248 .

7. Ibid.

8. Norman S. Endler, "Beyond Citation Counts: Developing Research Profiles," Canadian Psychological Review 19:152-57 (1978).

9. Robert L. Hemreich and others, "Making It in Academic Psychology: Demographic and Personality Correlates of Attainment," Journal of Personality and Social Psychology 39:896-908 (Nov. 1980).

10. David Lewis Smith, Thomas Roche, and William Snizek, "Quality of Graduate Productivity in Sociology as Measured by the Citation Index: A Longitudinal Overview," Research in Higher Education 13:343-52 (1980).

11. Norman S. Endler, J. Philippe Rushton, and Henry L. Roediger III, "Productivity and Scholarly Impact (Citations) of British, Canadian and U.S. Departments of Psychology (1975)," American Psychologist 33:1064-82 (Dec. 1978).

12. Richard C. Anderson, Francis Narin, and Paul McAllister, "Publication Ratings versus Peer Ratings of Universities," Journal of the American Society for Information Science 29:91-103 (March 1978).

\section{"Non-Depository" or Not: An Examination of the Designation of Non-Depository Titles in the Monthly Catalog of United States Government Publications}

\section{Steven D. Zink}

The Monthly Catalog of United States Government Publications includes citations to various government publications not distributed to federal depository libraries by the Superintendent of Documents. For the most part these elusive publications represent titles which are produced in regional government printing facilities or by private contractors for a government agency. Although this distinction alone does not preclude distribution to depository libraries, the sheer lack of available copies has frequently resulted in only an entry in the Monthly Catalog. ${ }^{1}$ The sole distinction in the Monthly Catalog entries between these non-depository titles and the publications distributed by the Superintendent of Documents is that the depository publications are distinguishable by an item selection number and a black dot $(\bullet)$. The black dot simply indicates that the title was available for distribution to deposi- tory libraries and that, at the very least, regional depositories, as required by law, have a copy of the publication. The item selection number is even more crucial. The nearly 5,500 current item numbers represent all of the possible categories of publications available which selective depository libraries may elect to receive. For example, item number 17 represents the Yearbook of Agriculture. If a depository would select that item number, it would annually receive the Yearbook of Agriculture. Therefore a depository is capable of establishing a selective profile to suit users' needs much like a library would with an approval plan. Absence of these two elements indicates that the publication was not available for distribution to depository libraries. In an effort to have as complete a collection of government publications as possible, many depositories have sought to acquire some or all of these non-

Steven D. Zink is head, Government Publications Department, University of Nevada Library, Reno. The author wishes to thank library intern Jeanne Smith for her assistance in compiling the data used in this article. 